\title{
LETTER
}

\section{Obituary for Professor Volker Römheld (1941-2013)}

\author{
Miroslav Nikolic • Ernest A. Kirkby • Ismail Cakmak
}

Received: 19 June 2014 / Accepted: 23 June 2014 / Published online: 4 July 2014

(C) Springer International Publishing Switzerland 2014

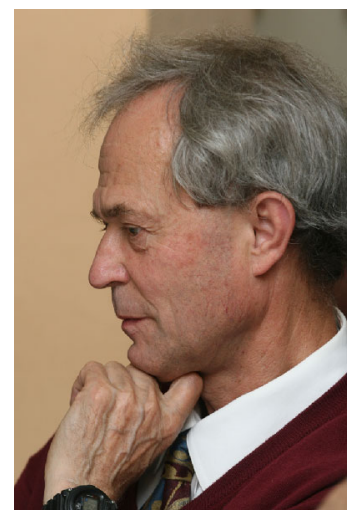

The death of Volker Römheld on the $27^{\text {th }}$ November 2013 brought deep sadness to all of us who knew him. Born in Schwaig near Nürnberg, Volker was a German agricultural scientist and plant physiologist with a high international reputation. He was a Professor of Plant

Responsible Editor: Hans Lambers.

M. Nikolic $(\bowtie)$

University of Belgrade,

POBox 33, 11030 Belgrade, Serbia

e-mail: mnikolic@imsi.bg.ac.rs

E. A. Kirkby

University of Leeds,

Leeds LS2 9JT, UK

I. Cakmak

Sabanci University,

34956 Tuzla, Istanbul, Turkey
Nutrition at Hohenheim University, where he worked for many years in close co-operation with his mentor, and later colleague, Horst Marschner during a time of outstanding research activity and achievement, which provided a source of present internationally recognized leaders in Plant Nutrition. For the last twenty years or so, Volker was a visiting professor at China Agricultural University (Beijing) and Zheijiang Agricultural University (Hangzhou). He very much enjoyed this contact with China, where he felt at home, in co-operating in the university research programs as well as supporting many young Chinese researchers in their first steps in science.

He published over 250 scientific papers in peerreviewed journals and book chapters, the vast majority of which focused on the various areas of his research activities: understanding the function, uptake and fertilization of micronutrients (in particular iron); significance of rhizosphere processes on nutrient acquisition (in particular phosphorus and micronutrients) and plant health; ecological aspects of fertilization and soil management (nitrogen forms, heavy metals and glyphosates); phytoremediation and recycling of agricultural and industrial byproducts. His papers have been cited more than 10,000 times with a very high $h$-index of 56 . He was invited to give keynote presentations at many international conferences and symposia. He supervised numerous MSc and PhD students and post-docs from different countries and cultures. As a teacher and mentor he excelled in his capacity to motivate students to think critically and creatively for themselves.

Volker was a Section Editor of Plant and Soil for many years and also served on the Editorial Board of 
several other journals (Journal of Plant Nutrition, BioMetals, Biology and Fertility of Soils). He was a member of the Deutsche Gesellschaft für Pflanzenernährung (DPG), Deutsche Bodenkundliche Gesellschaft (DBG), Society of Experimental Botany (SEB), American Society of Plant Physiology, American Society of Agronomy, American Society of Soil Sciences, American Society of Crop Sciences, and International Fertilizer Society (IFS).

Volker was a very humble person, who was incredibly clever, yet modest despite his vast knowledge, achievements and enormous contributions to plant nutrition. He was always pleased to be involved whether to join a field visit to a project in a rural area, or to deliver a paper at a scientific meeting, or to conduct a lively debate with young researchers and colleagues. He loved science and appreciated those people who wanted to apply their scientific knowledge to practical agriculture to help farmers grow more and better crops. His name is well-known among the crop consultants, agronomists and leading farmers in different countries including Brazil, China, Canada, India and Turkey. He paid great attention to the "real-life" situations in agriculture. When he visited rural areas, he liked to talk to the farmers and listened carefully to what they had to say so that he could address the specific issues or problems that they experienced in the field. From these close contacts with farmers and field agronomists he often generated new ideas and challenging research topics. In this respect a point that he stressed time and time again was the need for greater co-operation between all those involved in crop production, including agricultural scientists, those from the fertilizer industry, advisors and farmers. This he believed to be of benefit to all concerned, but of special importance to poor farmers working in inhospitable environments.

Volker was always ready to help with good advice and make a scientific contribution. His presentations were invariably of a very high standard and made in the most logical manner using the tables, figures and pictures that his wife Haoyan had prepared for him, although he did later become more independent in using his electronic notebook. For him the world was a village. He travelled a great deal spending much time on planes, and was often in great haste to catch his plane at the last minute. He was very busy and sometimes gave the impression of being a bit confused or disorganized, but he knew very well where to find any specific paper in his "chaotic" office and remembered details of results of experiments years after they had been published. His approach to discussion and, indeed, to his research was always to maintain an open mind, which was one of his great strengths. Volker felt that through proper co-operation in scientific work (and not through competition) one could "push" (as he liked to put it) for focused research. As always, he was pointing out urgent issues where further research was needed or where some particular fact should be noted or the results of research findings passed on to farmers.

Over the last five years of his life, Volker suffered from cancer, which progressively worsened, and it says much about his strength of character and fortitude that he remained dedicated to his work till the end. Even though seriously ill, during August 2013 he attended the International Plant Nutrition Colloquium (IPNC) in Istanbul; this was his last international meeting, which provided an opportunity to say farewell to friends and colleagues. Volker leaves his wife Haoyan, a daughter Ida (who was so close to his heart) and a son Michael to all of whom we extend our heart-felt condolences.

We will miss Volker greatly for his tremendous enthusiasm, optimism and good sense of humor, endless dedication and his vast knowledge and experience, as well as, of course, for the loss of a dear friend, teacher and colleague.

Miroslav Nikolic

Ernest A. Kirkby

Ismail Cakmak 